\title{
Fiberoptic laryngoscopy under general anesthesia in neonates
}

\author{
L.J. Hoeve ${ }^{1}$ and R.H.M. van Poppelen ${ }^{2}$ \\ Departments of 'Otorhinolaryngology and ${ }^{2}$ Anesthesiology, Sophia Children's Hospital, Rotterdam \\ (The Netherlands)
}

(Received 12 July 1989)

(Accepted 10 August 1989)

Key words: Fiberoptic laryngoscopy; Neonate; General anesthesia; Equipment

\begin{abstract}
In the Sophia Children's Hospital we perform fiberoptic laryngoscopy in neonates under general anesthesia without the use of muscle relaxants in the diagnostics of functional laryngeal disorders. The necessary diagnostic and anesthetic equipment is described. Special attention is paid to the way in which the fiberscope is introduced into the breathing circuit and into the child's airway. Several advantages over other methods are discussed. The procedure has proved to be easy, safe and informative.
\end{abstract}

\section{Introduction}

In Sophia Children's Hospital 150-200 laryngo-bronchoscopies are performed annually for various diagnostic and therapeutic reasons. In all therapeutic and in many diagnostic procedures we prefer to use the rigid bronchoscope with a telescope. The patient is given general anesthesia and is ventilated. The procedure always involves administration of a muscle relaxant. However, in children presenting with an inspiratory stridor it is necessary to evaluate the function of the larynx. This is not possible if muscle relaxants have been given, so in these cases we have to use a different method.

Direct laryngoscopy in a spontaneously breathing anesthetized child has the disadvantage of distortion of the larynx. Inserting the tip of the laryngoscope's hlade in the vallecula causes traction of the epiglottis, and consequently impedes

Correspondence: L.J. Hoeve, Department of Otorhinolaryngology, Sophia Children's Hospital, Gordelweg 160, 3038 GE Rotterdam. The Netherlands. 
examination of the mobility of laryngeal structures. Moreover, during this type of direct inspection inspired oxygen concentration, as well as the concentration of volatile anesthetics (and thereby anesthetic depth), are hard to control because of admixture of ambient air. This might limit the time available for the procedure, especially in the very young child.

Fiberoptic laryngoscopy under topical anesthesia in the awake child $[2,3]$ often leads only to discomfort of patient, parent and physician, while milder abnormalities of the larynx might be masked by active adduction efforts. Some authors advise to perform the procedure under heavy sedation [1].

Since two years we have been performing fiberoptic laryngoscopy under general anesthesia without the use of muscle relaxants in children in whom a functional evaluation of the larynx is indicated. Experience with some 15 patients has shown us that this technique does not have the disadvantages found in direct laryngoscopy under general anesthesia or fiberoptic laryngoscopy in the unanesthetized patient.

\section{Materials and Methods}

The patient is anesthetized by breathing $60-70 \%$ nitrous oxide and halothane in oxygen. When the depth of the anesthesia is sufficient to tolerate the procedure, the mask is taken from the face, and the fiberscope (Olympus $\mathrm{BF}$ type $3 \mathrm{C} 10$, diameter

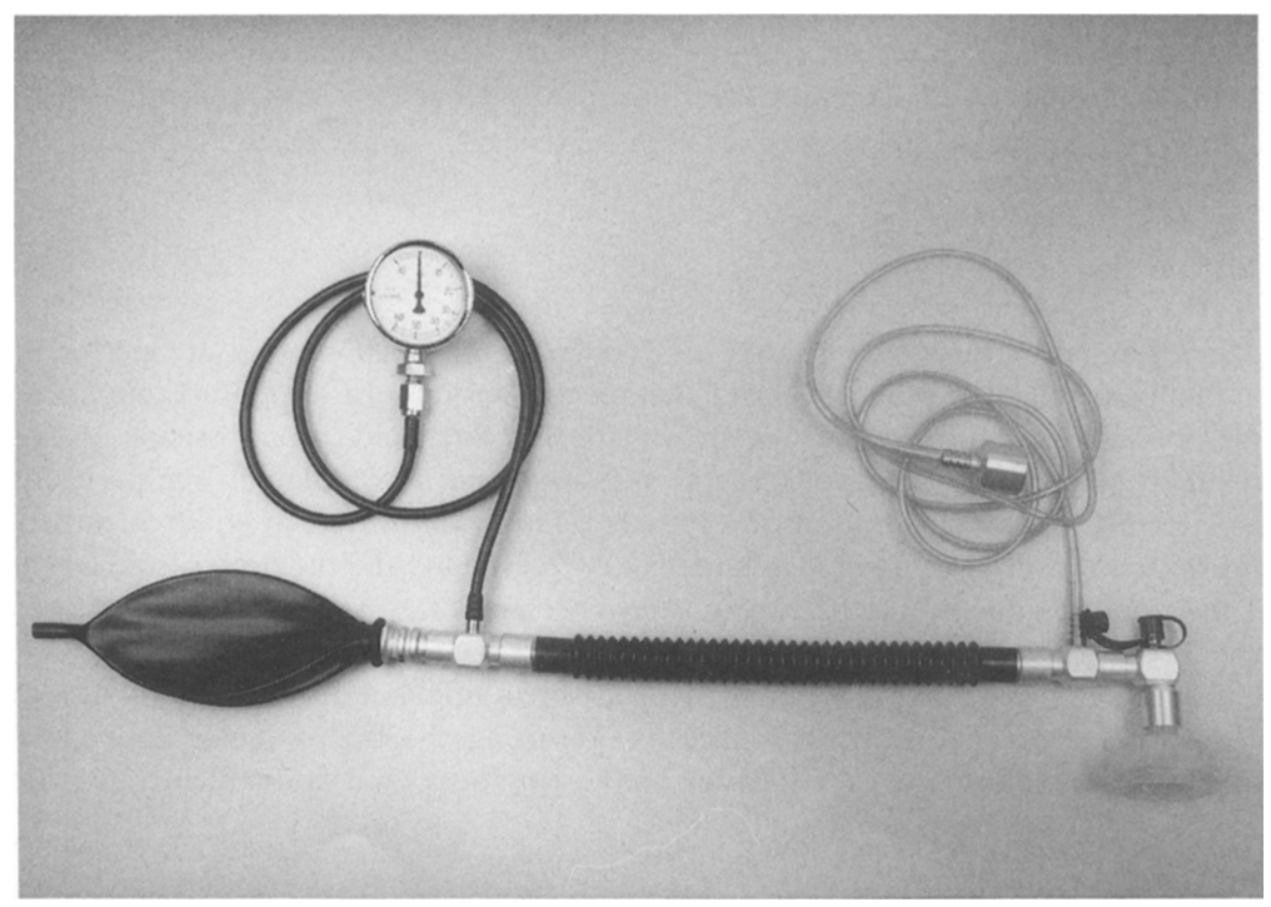

Fig. 1. Jackson-Rees system with a manometer and the breathing circuit elbow. 


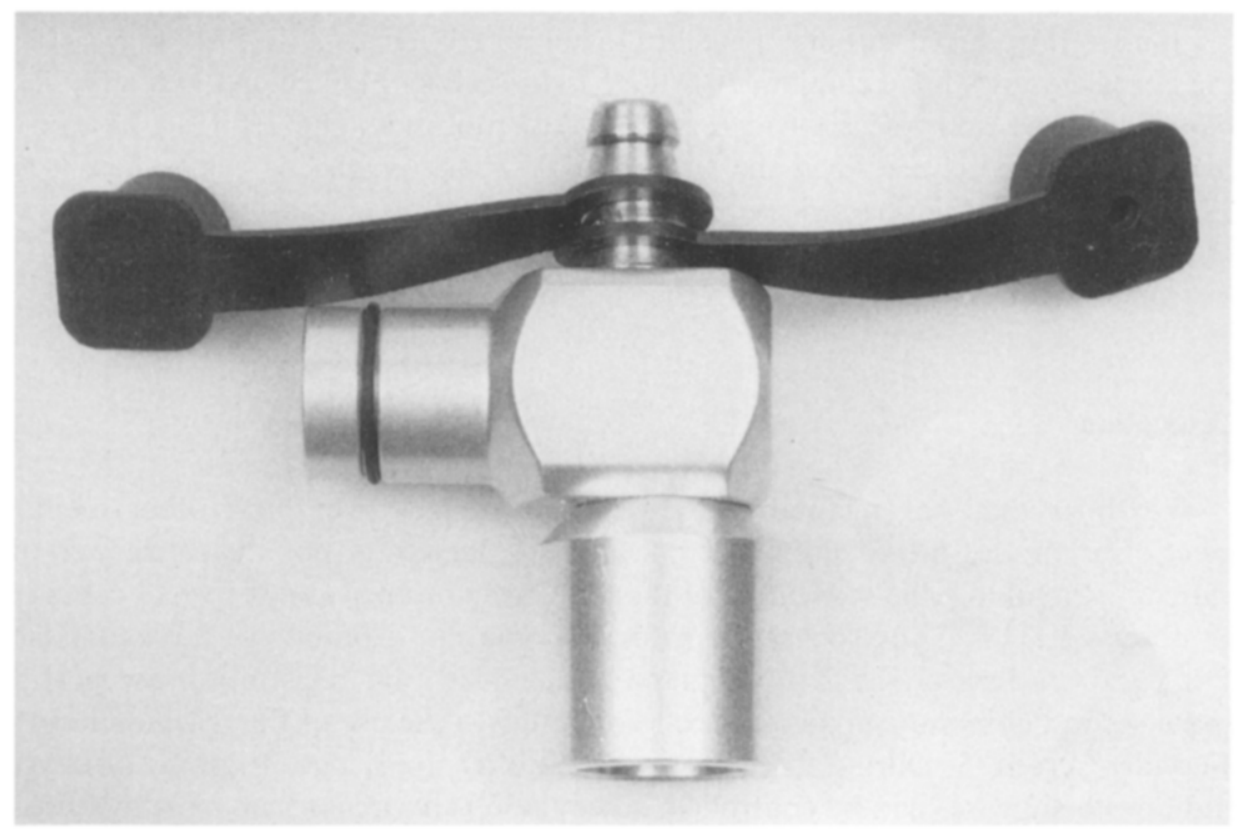

Fig. 2. Breathing circuit elbow with a perforated and an unperforated sealing cap.

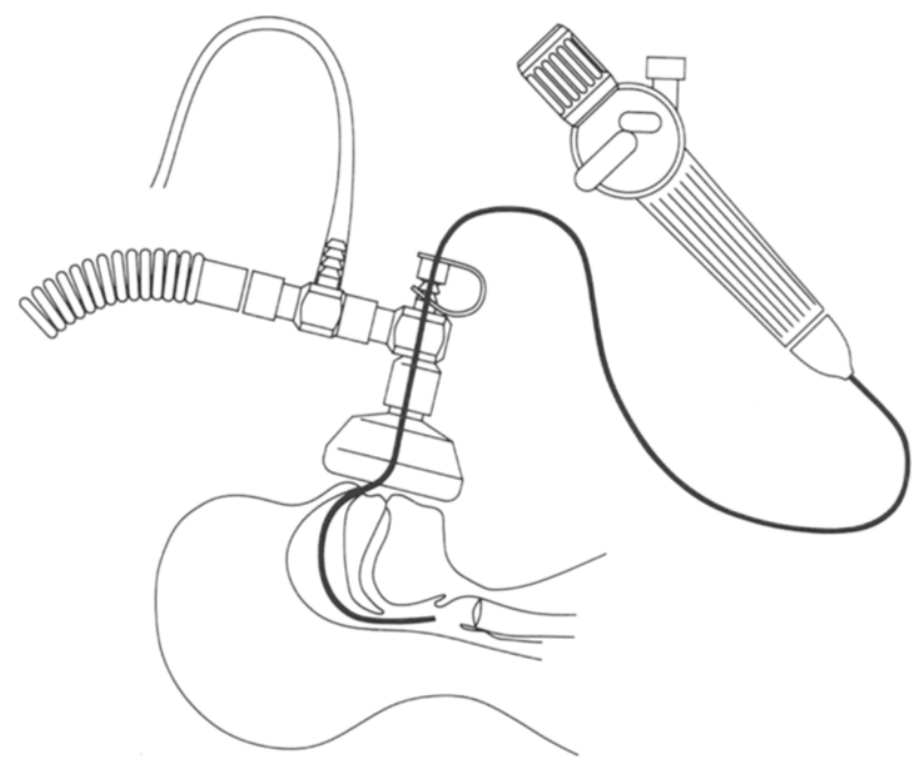

Fig. 3. Schematic representation of the anesthetic equipment and the fiberscope introduced into the laryngeal entrance. 
$3.5 \mathrm{~mm}$ ) is introduced through a custom-made breathing-circuit elbow. Fig. 1 shows the necessary anesthetic equipment. An air-tight seal is obtained as the fiberscope is passed into the elbowpiece through a perforated rubber sealing cap (Fig. 2). The tip of the fiberscope is placed in the nose, and the mask is applied to the face again. The fiberscope is then passed through the nose and pharynx, until an excellent view of the larynx is obtained (Fig. 3), with the patient breathing spontaneously. The instrument is never introduced into the subglottic area or the trachea.

\section{Discussion}

We think that our method has several advantages over both other methods mentioned in the introduction: 1. Because the larynx is not distorted, and the patient is breathing, the movement of the laryngeal entrance and the vocal cords can be observed. This is indispensable in for example the diagnosis of laryngomalacia and vocal cord paralysis. 2. Photography and video film registration are possible and a second observer can join the examination with the use of the teaching head or the video screen. 3. During the whole procedure inspired concentrations of oxygen and anesthetic gases can be controlled, since there is no major leak or admixture of ambient air. Therefore the procedure can take longer, and will be more precise. 4 . The depth of anesthesia can be adjusted by the anesthetist at any time during the procedure. The influence of the application of various levels of continuous positive airway pressure (CPAP) on the functional abnormality can be studied at the same time.

Passing the fiberscope through the vocal cords to examine the subglottic space and the trachea has to be condemned on account of laryngospasm (except when topical anesthesia is used) and obstruction of the airway, especially in the neonate. To examine these structures a rigid bronchoscope is introduced after a muscle relaxant has been given and the child is ventilated by hand.

In conclusion, anatomical disorders of the larynx, trachea and bronchial tree can be diagnosed perfectly well with the rigid bronchoscope. Fiberoptic laryngoscopy however is very useful in demonstrating functional disorders of the larynx. The procedure described has proved to be informative, safe and easy.

\section{Acknowledgements}

The authors thank Mrs. J. Charles for her contribution to the development of the procedure.

\section{References}

1 Nussbaum, E., Flexible fiberoptic bronchoscopy and laryngoscopy in infants and children, Laryngoscope, 93 (1983) 1073-1075. 
2 Selkin, S.G., Flexible fiberoptics and pediatric otolaryngology. A simple technique for examination and photodocumentation, Int. J. Pediatr. Otorhinolaryngol., 5 (1983) 325-333.

3 Silberman, H.D., The use of the flexible fiberoptic nasopharyngolaryngoscope in the pediatric upper airway, Otolaryngol. Clin. North Am., 11 (1978) 365-370. 